\title{
A Study on the Quality and Efficiency of Economic Development in Guangdong Province
}

\author{
$\mathrm{Mu} \mathrm{Yu}$ \\ South China University of Technology, Guangzhou, Guangdong, China \\ muyuhd@163.com
}

Keywords: Quality of Economic Development, Index Evaluation System, Entropy Method.

\begin{abstract}
Since the reform and opening up, China's national economy has maintained a rapid growth, GDP is increasing rapidly. But economic development are not only refers to the expansion of total economic output, but also in the promotion of qualitative aspects. Therefore, how to assess the quality of economic development of a country becomes important. As the forerunner of China's reform and opening up, Guangdong has become a large industrial province with strong economic strength. But in recent years, Guangdong is also facing bottlenecks in economic development, and development advantages have weakened. With the index evaluation system, this paper evaluates the quality and benefit of the current economic development of Guangdong province, find out the main driving force of its economic development and give some advice.
\end{abstract}

\section{广东省经济发展质量与效益研究}

\author{
穆羽 \\ 华南理工大学经济与贸易学院, 广州, 广东, 中国 \\ muyuhd@163.com
}

关键词：经济发展质量; 指标评价体系; 熵值法

中文摘要. 改革开放以来, 我国经济保持着高速增长, GDP实现快速增加。但是, 经济的发 展不仅是指总量的扩张, 更表现在其质的方面的提升和效益的提高。因此, 如何评价一个国 家或地区的经济发展质量变得愈发重要。广东作为中国改革开放的先行者, 已成为综合经济 实力较强的工业大省。但近年来，也面临经济发展瓶颈，发展优势有所减弱。本文通过构建 对经济发展质量的综合评价体系，对广东省现有经济发展的质量与效益进行综合评价，找出 其发展的主要推动力并提出政策建议。

\section{1. 引言}

中国改革开放30年来，GDP的增长引起了世界的瞩目，按经济规模已成为全球第二大经 济体。但在经济增长数量增加的同时, 经济发展的质量却出现了一定的滞后, 过去传统的增 长模式愈发不能适应变化了的国内外环境。另一方面, 在理论界, 传统的经济增长理论关注 的主要是经济增长数量的提高, 研究对象依然以GDP及其影响因素为主。学术界对经济发展 质量的界定及测度等关键性问题上依然没有形成理论共识。

针对上述理论和实践需要, 本文试图在现有文献的基础上, 选取我国经济发展的龙头省 份——广东省进行经济增长质量与效益的测度，从而对其经济发展情况进行评析。 
从国内外的研究来看, 早期对经济发展质量的研究主要停留在增长层面。1943年保罗・罗 森斯坦 - 罗丹提出大推进理论, 认为经济发展的必要初始条件是一定量的投资。1957年索洛 首次把技术进步这一因素吸收到经济增长理论中, 建立了现代增长理论的基石。1962年阿罗 推导出规模收益递增的生产函数，并且探讨了导致收益递增的原因。

随着社会的进步，人们在追求经济增长的过程中出现了诸多问题，人们也逐渐意识到经 济增长并不等同于经济发展, 质量比数量更为重要。范舒 (2001) 认为, 经济发展不仅包括 经济增长，更是指经济结构、政治结构、社会结构的变化以及各种结构内部的协调与优化, 是一个综合概念。黄泰岩 (2007) 指出经济发展方式不仅包括转变经济增长方式的内容, 还 应包括经济增长过程中的经济的质量与效益、经济结构以及能源的节约和环境的保护等。李 永友（2008）指出经济增长的质量高低更取决于经济结构。钞小静（2009）则指出, 经济增 长的结构以及经济增长的波动问题构成了经济增长质量的主要内容, 而从经济增长的结果来 看,经济增长质量主要涉及到经济增长的福利变化与成果分配, 以及资源利用和生态环境代价 问题。

国内学者也从不同的侧重点构建了关于经济发展质量的指标评价体系。钟学义（2001） 从经济增长的效率性、稳定性和平衡性三个方面构建了经济增长质量的衡量体系。梁亚民 (2002) 从经济增长方式转变、经济发展过程效率、经济产出结果和经济在增长潜能等方面 构建了经济发展质量评价体系。李永友（2008）从增长和结构两个指标来建立反映经济发展 质量的指标体系, 分别包括增长速度、增长效率、经济结构和社会结构四个一级指标。钞小 静 (2009) 从经济增长的结构、经济增长的稳定性、经济增长的福利变化与成果分配, 以及资 源利用和生态环境代价四个维度来构建综合评价体系。

\section{2. 经济发展质量与效益的内涵}

经济发展是一个多元化的概念。数量的变化在一定程度上仅能反映经济增长速度的快慢, 而经济发展质量则反映的是一定时期内国家或地区国民经济发展的优劣程度。发展经济并不 仅仅在于 “量的增加”，更重要的是 “质的提升”。

高质量的经济发展首先应该具有经济活力。这种活力一方面表现为经济的成长性，如人 均GDP增长率、地方财政收入增长率等; 另一方面表现为该地区经济对于资本、人才等要素 的吸引力。其次, 当地区经济发展保持在相对平稳的状态时, 其经济才有可能长期维持较高 速的增长; 反之, 剧烈的经济波动会带来产出的损失。最后, 经济发展的最终目的是增进国 民福利，提高人们的生活品质。因此经济发展成果为人民所共享。

所谓经济发展效益，指的是在各项经济活动中为达到一定的经济目标而投入的资本、劳 动力、自然资源等各种要素与所得成果的对比, 衡量的是经济发展过程中的投入产出关系。 这种产出既包括GDP的增长、国民收入的增加等合意产出, 又包括会对生态环境造成一定破 坏的废水、废气等非合意产出。从另一个角度来看, 经济发展的效益也可以分为社会效益和 生态效益两方面。社会效益衡量的是由自然资源和资本投入驱动转向效率驱动; 生态效益是 指经济增长过程中是否把资源环境的代价降低到最小。

\section{3. 经济发展质量与效益评价体系的构建与测量}

根据数据特点，本文采用熵值法对广东省经济发展质量指标体系进行赋权及评价。

\section{1 熵值法基本原理}

第一步，原始数据的收集与整理。

根据评价指标体系, 收集2005-2014年原始数据, 衡量广东省I年经济发展质量与效益, 评价体系共含 $\mathrm{n}$ 项评价指标, 则所得矩阵如下: 


$$
\mathbf{M}=\left[\begin{array}{ccc}
x_{11} & \ldots & x_{1 j} \\
\ldots & \ldots & \ldots \\
x_{i 1} & \ldots & x_{i j}
\end{array}\right]
$$

第二步，指标的标准化。

指标标准化后，计算第 $\mathrm{j}$ 项指标下 $\mathrm{i}$ 年份指标值的比重。

$$
y_{i j}=\frac{x^{\prime}{ }_{i j}}{\sum_{1}^{i} x^{\prime}{ }_{i j}}\left(0 \leq \mathrm{y}_{i j} \leq 1\right)
$$

第三步，计算指标的信息熵e和信息效用值 $\mathrm{d}$ 。

计算第 $\mathrm{j}$ 项指标的信息熵值。

$$
e_{j}=-k \sum_{1}^{i} y_{i j} \ln y_{i j}
$$

其中 $\mathrm{k}$ 为常数, $k=\frac{1}{\ln i}$ 。

计算某项指标的信息效用 $\mathrm{d}$ 。每个指标的效用价值取决于与该指标的信息熵之间的差值, 这个差值直接影响权重大小, 值越大, 对评价对象的重要性就越大, 权重也越大, 因此的计 算公式为:

$$
d_{j}=1-e_{j}
$$

第四步，计算评价指标权重 $\mathrm{Wj}$ 。

用熵值法估算每项指标的权重, 实际上就是利用信息熵的价值系数来确定其权重大小, 价值系数越高, 则相应指标的权重越大, 指标对评价对象的越重要, 对评价结果的贡献也越 大。第项指标的权重为:

$$
w_{j}=\frac{d_{j}}{\sum_{1}^{j} d_{j}}
$$

第五步，计算样本综合评价值U。

利用加权求和公式，计算评价对象的综合评价值：

$$
\mathrm{U}=\sum_{1}^{j} y_{i j} w_{j} * 100
$$

其中, $\mathrm{U}$ 为综合评价值, $\mathrm{U}$ 越大, 评价对象的效果越好。通过比较不同年份间 $\mathrm{U}$ 值的变化 得到相关评价结论。

\section{2 指标权重计算结果}

根据上文对经济发展质量与效益内涵的阐述, 按照系统性、层次性、数据可得性和以人 为本性的原则, 本文构建了衡量经济发展质量与效益的指标评价体系, 并采用摘值法计算结 果如下: 
表1广东省经济发展质量与效益综合评价指标权重

\begin{tabular}{|c|c|c|c|}
\hline \multirow{2}{*}{ 指标名称 } & \multicolumn{3}{|c|}{ 指标内容 } \\
\hline & 一级指标 & 二级指标 & 指标权重 \\
\hline \multirow{13}{*}{ 活力分析 } & \multirow{3}{*}{ 经济增长速度 } & 人均GDP同比增长率 & $2.48 \%$ \\
\hline & & 地方财政收入同比增长率 & $4.84 \%$ \\
\hline & & $\begin{array}{c}\text { 城镇居民人均可支配收入同比 } \\
\text { 增长率 }\end{array}$ & $1.56 \%$ \\
\hline & \multirow[b]{2}{*}{ 企业经营状况 } & 规模以上工业企业单位数 & $4.76 \%$ \\
\hline & & $\begin{array}{c}\text { 规模以上工业企业利润总额同 } \\
\text { 比增长率 }\end{array}$ & $3.71 \%$ \\
\hline & \multirow{5}{*}{$\begin{array}{c}\text { 科技、教育水平与 } \\
\text { 创新能力 }\end{array}$} & $\begin{array}{c}\text { 研究与实验发展(R\&D)经费占 } \\
\text { 本省生产总值比重 }\end{array}$ & $4.35 \%$ \\
\hline & & 教育支出占地方财政支出比重 & $2.51 \%$ \\
\hline & & $\begin{array}{c}\text { 科学技术支出占地方财政支出 } \\
\text { 比重 }\end{array}$ & $3.01 \%$ \\
\hline & & 专利授权数 & $4.72 \%$ \\
\hline & & 普通高校在校学生数 & $3.03 \%$ \\
\hline & \multirow{3}{*}{$\begin{array}{c}\text { 吸引外资与人才 } \\
\text { 情况 }\end{array}$} & 跨省净迁移率 & $1.78 \%$ \\
\hline & & 人口迁入率 & $6.22 \%$ \\
\hline & & 实际利用外商直接投资额 & $2.29 \%$ \\
\hline \multirow{3}{*}{ 平稳性分析 } & \multirow{2}{*}{ 波动情况 } & 经济增长波动系数 & $2.93 \%$ \\
\hline & & 通货膨胀率 & $3.79 \%$ \\
\hline & 就业情况 & 城镇登记失业率 & $6.16 \%$ \\
\hline \multirow{5}{*}{$\begin{array}{c}\text { 福利效应分 } \\
\text { 析 }\end{array}$} & \multirow{3}{*}{ 社会保障水平 } & 城乡居民最低生活保障金支出 & $4.79 \%$ \\
\hline & & 基本养老保险参保人数 & $4.17 \%$ \\
\hline & & 基本医疗保险参保人数 & $5.35 \%$ \\
\hline & \multirow{2}{*}{ 城乡差距 } & 城乡居民收入比 & $7.82 \%$ \\
\hline & & 城乡居民家庭恩格尔系数比 & $2.74 \%$ \\
\hline \multirow{6}{*}{ 效益分析 } & 资本产出比 & 单位产出所需资本存量 & $1.71 \%$ \\
\hline & 劳动产出比 & 单位产出所需劳动人口 & $2.63 \%$ \\
\hline & \multirow{2}{*}{ 能源产出比 } & 单位产出所需能耗 & $5.15 \%$ \\
\hline & & 单位产出所需水耗 & $2.75 \%$ \\
\hline & \multirow{2}{*}{ 环境产出比 } & 单位产出所产生的废水 & $2.77 \%$ \\
\hline & & 单位产出所产生的废气 & $1.98 \%$ \\
\hline
\end{tabular}

由上表可以看出通过熵值法所得的各项指标权重值基本维持在2\%-5\%-之间，这表明所选 的指标对于广东省经济发展质量都存在着非常重要的作用, 所构建的指标体系具有一定的合 理性。

\section{3 评价结果及分析}

从指标权重结果可以看出, 从2005年到2014年广东省经济发展过程中, 经济发展的活力 和福利效应对于广东经济的发展有着至关重要的影响, 这两方面的权重之和超过 $70 \%$ 。经济 发展的效益和平稳性情况权重分别为 $16.99 \%$ 和 $12.88 \%$ 。

在活力分析指标下，科技、教育水平与创新能力指标权重明显高于其他三项指标，说明 科技与教育水平的提高、创新能力的提升对于广东省经济活力的增加乃至广东省经济发展质 量与效益的提升具有关键作用; 从经济增长速度来看, 地方财政收入同比增长率指标权重达 到 $4.84 \%$, 是影响广东省经济增长速度最重要的指标; 科技、教育水平与创新能力是提升广东 省经济发展活力的最关键因素, 其中研究与实验发展 $(R \& D)$ 经费占本省生产总值比重、专利 授权数、和科学技术支出占地方财政支出比重分别占到 $4.35 \% 、 4.72 \%$ 、和 $3.01 \%$, 说明科研 投入的强度和科研成果的转化在很大程度上衡量着广东省的创新能力, 对于经济发展质量与 
效益有着重大影响; 从吸引外资与人才情况来看, 人口迁入率指标权重高达 $6.22 \%$, 说明人口 迁移所带来的劳动力变动对于广东省经济活力的增加至关重要。

经济发展的平稳性在指标评价体系中所占比重为 $12.88 \%$, 比重相对较低, 对于广东省经 济发展质量与效益的影响力较弱。说明考察期内, 广东省经济发展较为平稳, 未出现明显的 经济波动; 此外, 城镇登记失业率影响权重较高, 达到 $6.16 \%$, 说明就业局势的稳定对于广东 省经济的平稳性影响力较强。

福利效应指标权重 $24.87 \%$ 。从社会保障水平来看, 广东省社会保险支出不断增加, 覆盖 面不断扩大, 社会保障水平不断提升, 对广东省社会保障水平的提高和经济发展福利效用的 扩大均有重要作用; 此外, 城乡居民收入比权重高达 $7.82 \%$, 是整个指标评价体系中所占权重 最大的指标。这说明城乡居民收入比对于衡量城乡差距有着非常关键的作用, 城乡收入比的 降低, 城乡居民收入的提高, 尤其是农村居民纯收入的提高, 有助于缩小城乡差距的缩小, 改善居民生活水平，是提高经济发展质量的必要途径。

在经济发展的效益分析指标体系内, 可以发现能源产出比和环境产出比的改善是提升效 益水平的关键。单位产出所需能耗和水耗指标权重比重达 $5.15 \%$ 和 $2.75 \%$, 单位产出所产生的 废水和废气指标比重为 $2.77 \%$ 和 $1.98 \%$ 。

根据广东省经济发展质量与效益指标评价体系中各指标的权重，我们可以计算出考察期 内历年广东省经济发展质量的综合评价得分U，如下表所示:

表2 广东省经济发展综合评分

\begin{tabular}{|c|c|c|c|c|c|c|c|c|c|c|}
\hline 年份 & 2005 & 2006 & 2007 & 2008 & 2009 & 2010 & 2011 & 2012 & 2013 & 2014 \\
\hline $\begin{array}{c}\text { 综合 } \\
\text { 得分 }\end{array}$ & 5.55 & 7.63 & 8.73 & 7.04 & 11.33 & 11.93 & 10.40 & 12.43 & 15.96 & 16.64 \\
\hline
\end{tabular}

可以看出, 从2005年至2014年, 广东省经济发展质量与效益的综合评价得分整体上呈上 升趋势，2008年起受国际金融危机影响，评分有所下降，此后又恢复上升。总体而言，考察 期广东省的经济发展良好, 质量与效益均得到优化。

\section{4. 提高广东省经济发展质量与效益的政策建议}

\section{1 继续推进产业结构调整政策}

2008年起，广东省开始推行双转移政策，即 “珠三角劳动密集型产业向东西两翼、粤北 山区转移;而东西两翼、粤北山区的劳动力, 一方面向当地第二、第三产业转移, 另一方面其 中的一些较高素质劳动力, 向发达的珠三角地区转移。”

当前经济增速放缓, 产业转移的难度也有所上升。为了防止产业空心化倾向, 在进行产 业转移的同时，更要对传统产业进行技术改造，推动传统产业的转型升级。

尺寸标准为 10 磅，上下标6磅，次上下标5磅，符号 14 磅，次符号9磅。

\section{2 努力提高居民收入, 缩小城乡差距}

要大力增加居民可支配收入，建立起职工工资的正常增长机制，完善薪酬和分配制度， 扩大居民财富投资途, 将经济发展成果更多地惠及于民; 另一方面, 仍要不断缩小城乡差距, 促进区域间经济均衡发展，扩大经济发展的福利效应，不断改善民生。

\section{3 进一步加大科技投入和成果转化，实施创新驱动发展战略}

一是加大科技投入，充分发挥政府科技投入的 “杜杆效应” 和技术 “溢出效应” ; 二是 提高企业研发投入的积极性和主动性, 鼓励进行产品研发和技术升级改造。同时引导社会资 本投资科技创新, 形成多元化的科技投入体系。三是加强高等院校、科研院所与企业的合作， 加快科研成果向实际生产力的转化。 


\section{4 重视人才引进, 吸引优秀人力资源}

要继续实施人才强省战略, 建立健全人才引进和培养的保证机制, 形成培养和吸纳高层 次、高技能、创新型人才的常态机制。要通过政策扶持、资金投入、制度安排等措施大力开 发和提升本省劳动力资源, 同时以发展潜力、人才激励机制等优势吸引外省劳动力, 为经济 的持续发展提供强有力的人才资源保障。

\section{5 严格执行节能减排政策, 保障经济发展的可持续性}

虽然广东省在推进节能减排方面采取了积极的管制措施，能源产出比和环境产出比在逐 年下降, 但是环境退化成本的总量却在近几年随着总产出的增长而加速增长。特别是和同期 发达国家水平相比，在能源利用效率方面仍存在显著差距。

为了降低工业发展对资源环境的负面影响，一要大力推行新能源，促进新能源产业发展。 二是通过产业转移和技术升级改造, 减少污染排放。三是重视资源环境保护, 加强污染治理。

\section{References}

[1] Robert. M. Solow, A Contribution to the Theory of Economic Growth, The Quarterly Journal of Economics, pp. 65-94, 1956.

[2] Hall. R and Ch. Jones, Why do Some Countries Produce so Much More Output Per Worker than Others, The Quarterly Journal of Economics, Vol.144, pp.83-116, 1999

[3] De Melo. M, C. Denizer and A. Gelb, Patterns of Transition from Plan to Market, The World Bank Economic Review, Vol.10, pp.397-424,1996.

[4] Selowsky, M. and R. Martin, Policy Performance and Output Growth in the Transition Economics, The American Economic Review, Vol.87, pp.349-353, 1997.

[5] Pierre P, Combes, etc, The Integration of Regions and Nations, Economic Geography. pp.23-45, 2008. 